\title{
Ionospheric quasi-static electric field anomalies during seismic activity in August-September 1981
}

\author{
M. Gousheva ${ }^{1}$, D. Danov ${ }^{2}$, P. Hristov ${ }^{1}$, and M. Matova ${ }^{3}$ \\ ${ }^{1}$ Space Research Institute, Bulgarian Academy of Sciences, Sofia, Bulgaria \\ ${ }^{2}$ Solar-Terrestrial Influences Laboratory, Bulgarian Academy of Sciences, Sofia, Bulgaria \\ ${ }^{3}$ Geological Institute, Bulgarian Academy of Sciences, Sofia, Bulgaria
}

Received: 10 July 2008 - Revised: 18 September 2008 - Accepted: 18 September 2008 - Published: 5 January 2009

\begin{abstract}
The paper proposes new results, analyses and information for the plate tectonic situation in the processing of INTERCOSMOS-BULGARIA-1300 satellite data about anomalies of the quasi-static electric field in the upper ionosphere over activated earthquake source regions at different latitudes. The earthquake catalogue is made on the basis of information from the United State Geological Survey (USGS) website. The disturbances in ionospheric quasistatic electric fields are recorded by IESP-1 instrument aboard the INTERCOSMOS-BULGARIA-1300 satellite and they are compared with significant seismic events from the period 14 August-20 September 1981 in magnetically very quiet, quiet and medium quiet days. The main tectonic characteristics of the seismically activated territories are also taken in account. The main goal of the above research work is to enlarge the research of possible connections between anomalous vertical electric field penetrations into the ionosphere and the earthquake manifestations, also to propose tectonic arguments for the observed phenomena. The studies are represented in four main blocks: (i) previous studies of similar problems, (ii) selection of satellite, seismic and plate tectonic data, (iii) data processing with new specialized software and observations of the quasi-static electric field and (iiii) summary, comparison of new with previous results in our studies and conclusion. We establish the high informativity of the vertical component $E z$ of the quasi-static electric field in the upper ionosphere according observations by INTERCOSMOS-BULGARIA-1300 that are placed above considerably activated earthquake sources. This component shows an increase of about $2-10 \mathrm{mV} / \mathrm{m}$ above sources, situ-
\end{abstract}

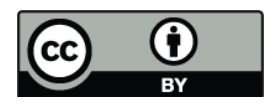

Correspondence to: M. Gousheva (gousheva@ space.bas.bg) ated on mobile structures of the plates. The paper discusses the observed effects. It is represented also a statistical study of ionospheric effects 5-15 days before and 5-15 days after the earthquakes with magnitude M 4.8-7.9.

\section{Introduction}

The study is devoted to statistical data of possible connections between anomalous ionospheric vertical quasi-static fields and the seismic activity. A $3-7 \mathrm{mV} / \mathrm{m}$ penetration in the vertical component in the upper ionospheric quasistatic electric fields from an electrostatic source were observed at first by Chmyrev et al. (1989) on the board INTERCOSMOS-BULGARIA-1300 satellite $15 \mathrm{~min}$ before an earthquake with $M=4.8$. Several observations of ionosphere precursors for earthquakes, including those connected with a pertubation of an electrostatic field in the atmosphere and ionosphere, was studied by Alperovich et al. (1999) and Kim et al. (1999). One of the most developed interpretations of these phenomena is based on the electrodynamic model about ionospheric precursors of earthquakes (Sorokin et al., 2001a; Sorokin and Chmyrev, 2002). This model provides an explanation of some electromagnetic and plasma phenomena connected to the effects of amplification of the DC electric field in the ionosphere. A theoretical model of the electric field disturbances caused by the conductivity currents in the atmosphere and the ionosphere initiated by external electric current was proposed by Sorokin and Yaschenko (2000) and Sorokin et al. (2001b). According to this model, the external current arises as a result of emanation of charged aerosols transported into the atmosphere by soil gases and the subsequent processes of

Published by Copernicus Publications on behalf of the European Geosciences Union. 
upward transfer, gravitational sedimentation and charge relaxation. Further development of this model includes a new method for computation of the electric field in the atmosphere and the ionosphere over active faults for arbitrary spatial distribution of external current in oblique magnetic field (Sorokin et al., 2005, 2006). In our previous papers (Gousheva et al., 2005a, b; 2006a, b, 2007, 2008a, b) on the basis of INTERCOSMOS-BULGARIA-1300 satellite data we found arguments for seismically-induced increases in the vertical components of the quasi-static electric field up to $2-10-15 \mathrm{mV} / \mathrm{m}$ in the near equatorial, low, middle and high latitude ionosphere. In this paper we present supplementary data about quasi-static electric field anomalies according INTERCOSMOS-BULGARIA-1300 satellite information over the Southern Atlantic Ocean, Tonga-New Hebrides region, Northern Islands of New Zealand, Indonesian region, Eastern Canada, Labrador Sea, Caribbean region, Central America, Western coast of South America, South-West Pacific Ocean, Kuril Islands, Aleutian Islands, Southern Pacific Ocean, Southern Iran during seismic events in AugustSeptember 1981.

\section{Satellite and seismic data selection}

The INTERCOSMOS-BULGARIA-1300 satellite is launched on 7 August 1981. It has a perigee of $825 \mathrm{~km}$, an apogee of $906 \mathrm{~km}$ and an orbital inclination of $81.2^{\circ}$. The INTERCOSMOS-BULGARIA-1300 satellite operates during two and a half years. The registrations of the quasi-static electric field are carried out by the IESP-1 instrument, as in our previous papers. The IESP-1 instrument measures the electric field using the Langmuir double probe floating potential method, identical with a voltmeter. There is a potential difference between two top-hat probes (Pedersen et al., 1984, 1998). Two sensors are applied to obtain the values of the both horizontal and one vertical component. The basis for the $X$ and $Y$ components is $7.5 \mathrm{~m}$ and for the $Z$ component $-1.8 \mathrm{~m}$. The dynamical range is $\pm 300 \mathrm{mV} / \mathrm{m}$ for the $X$ component, $\pm 600 \mathrm{mV} / \mathrm{m}$ - for the $Y$ one and $\pm 90 \mathrm{mV} / \mathrm{m}$ - for the $Z$ one. The sensitivity is $1 \mathrm{mV} / \mathrm{m}$ for each component. $E_{x}$ is the horizontal component almost parallel to the magnetic field line; $E_{y}$ is the horizontal component perpendicular to the magnetic field line; $E_{z}$ is the vertical component to the Earth surface. It is a difficult task to study the relations between the quasi-static electric field data and the seismic activity because the passes of satellite over the epicentre zones were rarely. The first task is to select the satellite data about ionospheric anomalies recorded over seismic zones with information for earthquakes in the time period 14 August-20 September 1981. Twenty six orbits are chosen above sources of 73 earthquakes complying with the following conditions:
- observations for satellite orbits over earthquake sources at different latitudes;

- observations for satellite orbits above areas with light, moderate, strong and major earthquakes in different tectonic structures of the planet;

- angular distances of $\Delta \lambda \leq 25^{\circ}$ between the earthquake epicentre and the closest point of the satellite orbit;

- seismic events in magnetically quiet days (the average geomagnetic activity index $K_{p} \leq 5$ );

- exclusion of events at the beginning or in the end of the orbit when there are calibrations and other operations that made the data unreliable;

- elimination of intervals with clear instrumental effects;

- exclusion of orbits that do not contain terminator crossing.

The second task is to select the seismic data. We consider that it is necessary to take in account the seismic situation 15 days before and after the monitoring for regions with strong seismic activity and 5 days before and after the monitoring for relatively quiet seismic regions. The earthquake data and related details for the same period are based on United State Geological Survey (USGS) website.

\section{Data processing and observations of the quasi-static electric field}

New specialized software is used for the processing of experimental data about quasi-static electric fields. We present our last results from observations of the quasi-static electric field on board INTERCOSMOS-BULGARIA-1300 satellite in the upper ionosphere $(h=800-900 \mathrm{~km})$ above earthquake sources in the Southern and Northern Hemisphere at different latitudes. In the topic, the arrows indicate the moments when the satellite passed at the closest distance $\Delta \lambda$ from the earthquake epicentre. The data are presented as a function of the Universal time (UT), satellite altitude (ALT), the geographic latitude and longitude (LAT, LONG), and the invariable latitude (Inv LAT).

\subsection{South Atlantic Ocean}

5 days before and after the passing of satellite (orbits 184, 198) and 5 days before and after the passing of satellite (orbits $305,347,348,403$ ) the seismic manifestations in the region is shown in Fig. 1a. Two events $\mathrm{EQ}_{1}$ and $\mathrm{EQ}_{46}$ (see Table 1) occurred near the Scotia Sea in the southern Atlantic Ocean. The territory is a complex area of marginal basins bordered by the Southern America and the Antarctic Plates. The boundary motion between the cited two large plates represents predominately left lateral strike-slip. The 
Table 1. Parameters of 73 earthquakes selected from USGS website and disturbances in the vertical component of the quasi-static electric fields observed by INTERCOSMOS-BULGARIA-1300 during limited period of time.

\begin{tabular}{|c|c|c|c|c|c|c|c|c|c|c|c|c|c|}
\hline \multirow[b]{2}{*}{ No } & & Earthqual & Catalog & & & & \multirow[t]{2}{*}{ Orbits } & \multirow[t]{2}{*}{ Date } & \multirow[t]{2}{*}{$\Delta t, h$} & \multirow[t]{2}{*}{$\begin{array}{l}\text { Indexof } \\
\text { geomagnetic } \\
\text { activity Kp }\end{array}$} & \multirow[t]{2}{*}{$\begin{array}{l}\text { Disturbances in } \mathrm{E}_{z} \\
\text { componentof the quasi-static } \\
\text { electric fields, } \mathrm{mV} / \mathrm{m} \text {; } \\
\text { Foreshocks and aftershocks }\end{array}$} & \multicolumn{2}{|c|}{$\begin{array}{l}\text { Distance from } \\
\text { satellite to } \\
\text { epicentrer, km } \\
\Delta \lambda, \operatorname{deg}\end{array}$} \\
\hline & $\mathrm{D}, \mathrm{M}, \mathrm{Y}$ & $\begin{array}{l}\text { Time, UTC, } \\
\text { hhmmss.mm }\end{array}$ & Lat, & Long, & Depth, km & $M$ & & & & & & & \\
\hline $\mathrm{EQ}_{1}$ & 19810817 & 050444 & -60.01 & -25.89 & 33 & 5.0 & 184 & 20.08 .1981 & $+80: 30$ & 2 & 5 & 1214 & 07.40 \\
\hline & & & & & & & 198 & 21.08.1981 & $+104: 15$ & 4 & 5 & 1300 & 08.38 \\
\hline $\mathrm{EQ}_{2}$ & 19810817 & 170741 & -25.45 & -179.05 & 383 & 5.5 & 170 & 19.08.1981 & $+44: 15$ & 3 & 2 & 1140 & 06.70 \\
\hline & & & & & & & 213 & 22.08 .1981 & $+96: 18$ & 3 & uncertain & 1903 & 14.09 \\
\hline $\mathrm{EQ}_{3}$ & 19810817 & 191243 & -30.14 & -177.53 & 33 & 5.1 & 170 & 19.08.1981 & $+42: 11$ & 3 & 3, cumulative effect of $\mathrm{EQ}_{3,7}$ & 1067 & 05.70 \\
\hline & & & & & & & 213 & 22.08 .1981 & $+94: 14$ & 3 & uncertain & 1910 & 14.89 \\
\hline $\mathrm{EQ}_{4}$ & 1981.08 .18 & 031252 & -4.03 & 127.32 & 41 & 5.0 & 215 & 22.08 .1981 & $+113: 27$ & 3 & foreshock of $\mathrm{EQ}_{13}$ & 1875 & 14.32 \\
\hline $\mathrm{EQ}_{5}$ & 1981.08 .18 & 052934 & -4.09 & 127.33 & 33 & 5.1 & 215 & 22.08 .1981 & $+108: 27$ & 3 & 8, cumulative effect of $\mathrm{EQ}_{5,33}$ & 1876 & 14.33 \\
\hline $\mathrm{EQ}_{6}$ & 19810818 & 132754 & 65.84 & -89.89 & 18 & 5.1 & 193 & 21.08.1981 & $+62: 28$ & 2 & 5 & 1780 & 12.98 \\
\hline $\mathrm{EQ}_{7}$ & 19810819 & 014107 & -33.46 & 179.66 & 184 & 5.1 & 170 & 19.08.1981 & $+11: 43$ & 3 & 3, cumulative effect of $\mathrm{EQ}_{3,7}$ & 1342 & 09.00 \\
\hline & & & & & & & 213 & 22.08 .1981 & $+60: 44$ & 3 & absent & 1655 & 12.00 \\
\hline $\mathrm{EQ}_{8}$ & 19810819 & 030107 & -24.12 & 180.00 & 507 & 4.8 & 170 & 19.08 .1981 & $+10: 21$ & 3 & absent & 1207 & 07.50 \\
\hline & & & & & & & 213 & 22.08 .1981 & $+55: 24$ & 3 & absent & 1821 & 13.08 \\
\hline $\mathrm{EQ}_{9}$ & 19810819 & 060624 & -22.98 & 170.50 & 25 & 5.6 & 170 & 19.08 .1981 & $+07: 15$ & 3 & 10 & 879 & 16.00 \\
\hline & & & & & & & 213 & 22.08 .1981 & $+87: 53$ & 3 & 5 & 974 & 04.57 \\
\hline $\mathrm{EQ}_{10}$ & 19810819 & 122533 & -49.79 & 164.23 & 33 & 4.8 & 213 & 22.08 .1981 & $+50: 05$ & 3 & 5 & 1102 & 06.20 \\
\hline $\mathrm{EQ}_{11}$ & 19810820 & 021948 & -11.48 & 166.16 & 70 & 5.0 & 213 & 22.08 .1981 & $+53: 56$ & 2 & uncertain & 933 & 01.03 \\
\hline $\mathrm{EQ}_{12}$ & 19810820 & 044847 & -22.93 & -70.55 & 23 & 4.9 & 250 & 25.08 .1981 & $+120: 25$ & 3 & 7 & 1569 & 11.00 \\
\hline & & & & & & & 251 & 25.08 .1981 & $+125: 36$ & 3 & 7 & 1853 & 14.00 \\
\hline $\mathrm{EQ}_{13}$ & 19810820 & 151003 & -27.14 & -179.15 & 346 & 4.9 & 170 & 22.08 .1981 & $-25: 47$ & 3 & absent & 1308 & 08.60 \\
\hline & & & & & & & 213 & 22.08 .1981 & $+23: 25$ & 3 & absent & 1695 & 12.60 \\
\hline $\mathrm{EQ}_{14}$ & 19810821 & 011508 & -34.11 & -70.09 & 117 & 4.9 & 250 & 25.08 .1981 & $+97: 02$ & 3 & 8 & 1392 & 09.58 \\
\hline & & & & & & & 251 & 25.08 .1981 & $+101: 44$ & 3 & 8 & 2196 & 17.35 \\
\hline $\mathrm{EQ}_{15}$ & 19810821 & 182414 & -18.77 & -174.51 & 33 & 4.8 & 170 & 19.08 .1981 & $-54: 03$ & 3 & absent & 839 & 01.50 \\
\hline & & & & & & & 213 & 22.08 .1981 & $+20: 04$ & 3 & absent & 1479 & 10.40 \\
\hline $\mathrm{EQ}_{16}$ & 19810821 & 225240 & -26.50 & -114.76 & 10 & 5.1 & 196 & 21.08 .1981 & $-13: 20$ & 2 & 8 & 909 & 03.40 \\
\hline & & & & & & & 244 & 24.08 .1981 & $+68: 46$ & 4 & absent & 1394 & 09.23 \\
\hline $\mathrm{EQ}_{17}$ & 19810822 & 234741 & -35.83 & -103.30 & 10 & 5.2 & 196 & 21.08 .1981 & $-14: 12$ & 2 & 10 & 1509 & 10.32 \\
\hline & & & & & & & 244 & 24.08 .1981 & $+43: 49$ & 4 & absent & 953 & 03.42 \\
\hline & & & & & & & 251 & 25.08 .1981 & $+55: 13$ & 3 & 8 & 2020 & 15.72 \\
\hline $\mathrm{EQ}_{18}$ & 19810823 & 015950 & -22.06 & 170.95 & 100 & 5.8 & 170 & 19.08.1981 & $-84: 21$ & 3 & 12 & 879 & 16.00 \\
\hline & & & & & & & 213 & 22.08 .1981 & $-14: 35$ & 3 & $9-10$ & 1022 & 05.10 \\
\hline $\mathrm{EQ}_{19}$ & 19810823 & 120026 & 48.71 & 157.39 & 40 & 6.0 & 283 & 27.08.1981 & $+91: 57$ & 5 & 10 & 1160 & 09.03 \\
\hline $\mathrm{EQ}_{20}$ & 19810823 & 180704 & -35.67 & 178.25 & 164 & 4.8 & 170 & 19.08 .1981 & $+100: 42$ & 3 & absent & 1507 & 10.30 \\
\hline & & & & & & & 213 & 22.08 .1981 & $-27: 39$ & 3 & absent & 1479 & 10.40 \\
\hline $\mathrm{EQ}_{21}$ & 19810823 & 195632 & -17.07 & 120.52 & 33 & 4.8 & 215 & 22.08 .1981 & $-26: 10$ & 3 & 8 & 1110 & 06.39 \\
\hline $\mathrm{EQ}_{22}$ & 19810823 & 234528 & -63.57 & -167.21 & 10 & 5.0 & 170 & 19.08.1981 & $+106: 15$ & 3 & 5 & 1045 & 05.40 \\
\hline & & & & & & & 213 & 22.08 .1981 & $-33: 11$ & 3 & 10 & 1298 & 08.50 \\
\hline $\mathrm{EQ}_{23}$ & 19810824 & 112033 & 61.22 & -59.01 & 10 & 4.8 & 193 & 21.08.1981 & $-79: 19$ & 2 & 10 & 946 & 02.84 \\
\hline $\mathrm{EQ}_{24}$ & 19810824 & 154627 & 51.50 & -178.35 & 56 & 5.2 & 240 & 24.08 .1981 & $-00: 52$ & 3 & 10 & 1128 & 06.09 \\
\hline & & & & & & & 283 & 27.08.1981 & $+72: 21$ & 5 & uncertain & 2244 & 18.00 \\
\hline $\mathrm{EQ}_{25}$ & 19810825 & 015849 & -23.51 & -179.91 & 550 & 4.8 & 213 & 22.08 .1981 & $-25: 34$ & 3 & absent & 1880 & 14.00 \\
\hline $\mathrm{EQ}_{26}$ & 19810825 & 052021 & -34.61 & -179.46 & 68 & 5.4 & 213 & 22.08 .1981 & $-59: 52$ & 3 & 4 & 1724 & 12.90 \\
\hline $\mathrm{EQ}_{27}$ & 19810825 & 071658 & -22.89 & -175.85 & 33 & 5.9 & 213 & 22.08 .1981 & $-62: 02$ & 3 & absent & 2686 & 21.78 \\
\hline $\mathrm{EQ}_{28}$ & 19810825 & 072245 & -22.90 & -175.90 & 33 & 5.7 & 213 & 22.08 .1981 & $-62: 62$ & 3 & absent & 2686 & 21.78 \\
\hline $\mathrm{EQ}_{29}$ & 19810825 & 165438 & 6.93 & -76.59 & 33 & 5.2 & 250 & 25.08 .1981 & $-11: 05$ & 5 & 5 & 1641 & 12.00 \\
\hline & & & & & & & 251 & 25.08 .1981 & $-10: 06$ & 5 & 4 & 1788 & 13.00 \\
\hline $\mathrm{EQ}_{30}$ & 19810825 & 172907 & 7.01 & -76.58 & 33 & 5.1 & 250 & 25.08 .1981 & $-12: 23$ & 3 & aftershock $\mathrm{EQ}_{29}$ & 1639 & 12.00 \\
\hline & & & & & & & 251 & 25.08 .1981 & $-10: 41$ & 3 & aftershock $E_{29}$ & 1790 & 13.50 \\
\hline $\mathrm{EQ}_{31}$ & 19810825 & 214025 & -11.76 & 166.59 & 150 & 4.9 & 213 & 22.08 .1981 & $-76: 20$ & 3 & absent & 933 & 01.03 \\
\hline $\mathrm{EQ}_{32}$ & 19810827 & 054509 & 44.99 & 146.09 & 197 & 4.8 & 283 & 27.08.1981 & +07.11 & 5 & absent & 2331 & 18.39 \\
\hline $\mathrm{EQ}_{33}$ & 19810827 & 075455 & -6.46 & 129.89 & 46 & 4.9 & 215 & 22.08 .1981 & $-107: 21$ & 3 & 8, cumulative effect of $\mathrm{EQ}_{5,33}$ & 2126 & 17.00 \\
\hline $\mathrm{EQ}_{34}$ & 19810827 & 135240 & 6.88 & -76.72 & 33 & 4.8 & 250 & 25.08 .1981 & $+56: 47$ & 3 & aftershock $\mathrm{EQ}_{29}$ & 1641 & 12.00 \\
\hline & & & & & & & 251 & 25.08 .1981 & $+55: 04$ & 3 & aftershock $\mathrm{EQ}_{29}$ & 1788 & 13.00 \\
\hline $\mathrm{EQ}_{35}$ & 19810828 & 123651 & 52.42 & -169.28 & 39 & 5.1 & 240 & 24.08 .1981 & $+96: 00$ & 3 & uncertain & 1114 & 05.94 \\
\hline $\mathrm{EQ}_{36}$ & 19810829 & 001549 & 19.28 & -64.85 & 33 & 4.8 & 250 & 25.08 .1981 & $-85: 13$ & 3 & absent & 836 & 00.79 \\
\hline & & & & & & & 349 & 01.09 .1981 & $+52: 55$ & 1 & absent & 2123 & 16.66 \\
\hline $\mathrm{EQ}_{37}$ & 19810829 & 074151 & -2.20 & 100.85 & 57 & 4.9 & 258 & 25.08 .1981 & $-84: 56$ & 3 & $2-3$ & 1386 & 09.50 \\
\hline $\mathrm{EQ}_{38}$ & 19810829 & 181747 & 12.89 & -87.85 & 33 & 5.2 & 251 & 25.08 .1981 & $-101: 57$ & 3 & absent & 889 & 02.79 \\
\hline & & & & & & & 349 & 01.09.1981 & $-58: 55$ & 1 & absent & 1145 & 06.84 \\
\hline $\mathrm{EQ}_{39}$ & 19810830 & 205008 & 6.88 & -76.58 & 33 & 4.9 & 250 & 25.08 .1981 & $-105: 14$ & 3 & aftershock $\mathrm{EQ}_{29}$ & 1641 & 12.00 \\
\hline & & & & & & & 251 & 25.08 .1981 & $-106: 54$ & 2 & aftershock $\mathrm{EQ}_{29}$ & 1788 & 13.00 \\
\hline $\mathrm{EQ}_{40}$ & 19810901 & 072302 & -15.13 & -173.28 & 33 & 5.8 & 170 & 19.08.1981 & $\sim-306$ & 3 & foreshock of $\mathrm{EQ}_{41}$ & 822 & 00.28 \\
\hline & & & & & & & 527 & 13.09.1981 & $\sim+300$ & 1 & foreshock of $\mathrm{EQ}_{41}$ & 2519 & 19.61 \\
\hline $\mathrm{EQ}_{41}$ & 19810901 & 092931 & -14.96 & -173.08 & 25 & 7.9 & 170 & 19.08.1981 & $\sim-306$ & 3 & 18 & 822 & 00.28 \\
\hline & & & & & & & 527 & 13.09.1981 & $\sim+300$ & 1 & 12 & 2519 & 19.61 \\
\hline
\end{tabular}


Table 1. Continued.

\begin{tabular}{|c|c|c|c|c|c|c|c|c|c|c|c|c|c|}
\hline \multirow[b]{2}{*}{ No } & & Earthquak & e Catalog & & & & \multirow[t]{2}{*}{ Orbits } & \multirow[t]{2}{*}{ Date } & \multirow[t]{2}{*}{$\Delta t, h$} & \multirow[t]{2}{*}{$\begin{array}{l}\text { Indexof } \\
\text { geomagnetic } \\
\text { activity Kp }\end{array}$} & \multirow[t]{2}{*}{$\begin{array}{l}\text { Disturbances in } \mathrm{E}_{z} \\
\text { componentof the quasi-static } \\
\text { electric fields, } \mathrm{mV} / \mathrm{m} \text {; } \\
\text { Foreshocks and aftershocks }\end{array}$} & \multicolumn{2}{|c|}{$\begin{array}{l}\text { Distance from } \\
\text { satellite to } \\
\text { epicentrer, km } \\
\Delta \lambda, \text { deg }\end{array}$} \\
\hline & $\mathrm{D}, \mathrm{M}, \mathrm{Y}$ & $\begin{array}{l}\text { Time, UTC, } \\
\text { hhmmss.mm }\end{array}$ & Lat, & Long, & Depth, km & $M$ & & & & & & & \\
\hline $\mathrm{EQ}_{42}$ & 19810901 & 095932 & -15.15 & -173.26 & 33 & 5.6 & 527 & 13.09.1981 & $\sim+300$ & 1 & aftershock of $\mathrm{EQ}_{41}$ & 2519 & 19.61 \\
\hline $\mathrm{EQ}_{43}$ & 19810901 & 105903 & -15.01 & -173.36 & 33 & 5.2 & 527 & 13.09 .1981 & $\sim+300$ & 1 & aftershock of $\mathrm{EQ}_{41}$ & 2519 & 19.61 \\
\hline $\mathrm{EQ}_{44}$ & 19810901 & 123914 & -15.05 & -173.31 & 33 & 4.8 & 527 & 13.09.1981 & $\sim+300$ & 1 & aftershock of $\mathrm{EQ}_{41}$ & 2519 & 19.61 \\
\hline $\mathrm{EQ}_{45}$ & 19810901 & 152436 & -15.23 & -173.07 & 33 & 4.8 & 527 & 13.09 .1981 & $\sim+300$ & 1 & aftershock of $\mathrm{EQ}_{41}$ & 2519 & 19.61 \\
\hline \multirow[t]{4}{*}{$\mathrm{EQ}_{46}$} & 19810901 & 155557 & -58.71 & -25.36 & 115 & 4.8 & 305 & 29.08 .1981 & $+61: 06$ & 3 & absent & 882 & 02.68 \\
\hline & & & & & & & 347 & 01.09 .1981 & $-12: 47$ & 0 & 10 & 1123 & 06.46 \\
\hline & & & & & & & 348 & 01.09 .1981 & $-12: 00$ & 4 & 8 & 1896 & 14.43 \\
\hline & & & & & & & 403 & 05.09.1981 & $+81: 19$ & 4 & 8 & 1597 & 11.57 \\
\hline $\mathrm{EQ}_{47}$ & 19810901 & 183847 & -15.31 & -173.30 & 33 & 5.7 & 527 & 13.09.1981 & $\sim+300$ & 1 & aftershock of $\mathrm{EQ}_{41}$ & 2519 & 19.61 \\
\hline $\mathrm{EQ}_{48}$ & 19810901 & 235545 & -15.22 & -173.17 & 33 & 5.6 & 527 & 13.09.1981 & $\sim+300$ & 1 & aftershock of $\mathrm{EQ}_{41}$ & 2519 & 19.61 \\
\hline $\mathrm{EQ}_{49}$ & 19810902 & 002354 & -55.31 & -1.67 & 10 & 5.1 & 347 & 01.09 .1981 & $-22: 12$ & 0 & 10 & 2034 & 15.75 \\
\hline $\mathrm{EQ}_{50}$ & 19810902 & 003427 & -15.41 & -172.86 & 33 & 4.8 & 527 & 13.09 .1981 & $\sim+276$ & 1 & aftershock of $\mathrm{EQ}_{41}$ & 2519 & 19.61 \\
\hline $\mathrm{EQ}_{51}$ & 19810902 & 021025 & -15.55 & -172.59 & 33 & 4.8 & 527 & 13.09.1981 & $\sim+276$ & 1 & aftershock of $\mathrm{EQ}_{41}$ & 2519 & 19.61 \\
\hline $\mathrm{EQ}_{52}$ & 19810902 & 062547 & -15.08 & -173.01 & 33 & 4.8 & 527 & 13.09.1981 & $\sim+276$ & 1 & aftershock of $\mathrm{EQ}_{41}$ & 2519 & 19.61 \\
\hline $\mathrm{EQ}_{53}$ & 19810902 & 084421 & -15.47 & -172.97 & 33 & 5.6 & 527 & 13.09.1981 & $\sim+276$ & 1 & aftershock of EQ 41 & 2519 & 19.61 \\
\hline $\mathrm{EQ}_{54}$ & 19810902 & 103052 & -14.91 & -173.68 & 33 & 5.3 & 527 & 13.09.1981 & $\sim+276$ & 1 & aftershock of $\mathrm{EQ}_{41}$ & 2519 & 19.61 \\
\hline $\mathrm{EQ}_{55}$ & 19810903 & 021255 & -38.79 & -92.40 & 10 & 4.8 & 349 & 01.09.1981 & $+47: 56$ & 1 & 8 & 2110 & 16.55 \\
\hline $\mathrm{EQ}_{56}$ & 19810903 & 053544 & 43.62 & 147.03 & 45 & 6.6 & 283 & 27.08 .1981 & $-153: 38$ & 5 & 15 & 2274 & 18.00 \\
\hline $\mathrm{EQ}_{57}$ & 19810903 & 062814 & 43.58 & 146.87 & 33 & 5.0 & 283 & 27.08.1981 & $-158: 31$ & 5 & absent & 2292 & 18.00 \\
\hline $\mathrm{EQ}_{58}$ & 19810905 & 080035 & 43.68 & 146.73 & 33 & 4.9 & 283 & 27.08 .1981 & $-160: 03$ & 5 & absent & 2303 & 18.00 \\
\hline \multirow[t]{2}{*}{$\mathrm{EQ}_{59}$} & 19810903 & 080901 & 11.85 & -87.46 & 48 & 5.1 & 349 & 01.09 .1981 & $-55: 24$ & 1 & absent & 1290 & 08.00 \\
\hline & & & & & & & 405 & 05.09 .1981 & $+44: 17$ & 3 & absent & 1840 & 14.00 \\
\hline \multirow[t]{2}{*}{$\mathrm{EQ}_{60}$} & 19810904 & 082306 & -15.69 & -13.10 & 10 & 5.1 & 347 & 01.09.1981 & $-78: 02$ & 0 & $2-3$ & 1847 & 14.13 \\
\hline & & & & & & & 403 & 05.09 .1981 & $+19: 40$ & 4 & 2 & 1295 & 08.00 \\
\hline \multirow[t]{2}{*}{$\mathrm{EQ}_{61}$} & 19810906 & 164319 & -36.17 & -100.70 & 10 & 5.4 & 482 & 10.09 .1981 & $+95: 05$ & 3 & 3 & 2212 & 17.10 \\
\hline & & & & & & & 483 & 10.09 .1981 & $+96: 49$ & 3 & 2 & 1320 & 08.15 \\
\hline $\mathrm{EQ}_{62}$ & 19810910 & 143726 & -22.67 & -179.34 & 528 & 4.8 & 527 & 13.09 .1981 & $+73: 41$ & 1 & absent & 3072 & 24.93 \\
\hline $\mathrm{EQ}_{63}$ & 19810910 & 224300 & -23.26 & -177.11 & 33 & 5.2 & 527 & 13.09.1981 & $+69: 36$ & 1 & absent & 2819 & 22.64 \\
\hline $\mathrm{EQ}_{64}$ & 19810911 & 120704 & -15.03 & -173.61 & 33 & 4.9 & 527 & 13.09 .1981 & $+56: 13$ & 1 & absent & 2531 & 20.02 \\
\hline $\mathrm{EQ}_{65}$ & 19810912 & 022916 & 27.85 & 56.97 & 33 & 4.8 & 505 & 12.09 .1981 & $+04: 43$ & 3 & 5 & 959 & 03.00 \\
\hline \multirow[t]{3}{*}{$\mathrm{EQ}_{66}$} & 19810915 & 224412 & -27.66 & -71.57 & 33 & 4.9 & 482 & 10.09 .1981 & $-123: 44$ & 3 & absent & 1320 & 08.50 \\
\hline & & & & & & & 546 & 15.09 .1981 & $+18: 16$ & 2 & absent & 1534 & 10.00 \\
\hline & & & & & & & 602 & 19.09 .1981 & $+79: 22$ & 5 & absent & 1610 & 11.00 \\
\hline \multirow[t]{3}{*}{$\mathrm{EQ}_{67}$} & 19810916 & 022348 & -8.85 & -109.13 & 10 & 4.9 & 505 & 12.09 .1981 & $-20: 40$ & 3 & 5 & 1068 & 05.96 \\
\hline & & & & & & & 547 & 15.09 .1981 & $-20: 47$ & 2 & 10 & 833 & 01.81 \\
\hline & & & & & & & 581 & 17.09 .1981 & $+40: 34$ & 1 & $3-4$ & 1596 & 11.00 \\
\hline $\mathrm{EQ}_{68}$ & 19810917 & 150929 & -15.20 & -173.11 & 33 & 4.8 & 527 & 13.09.1981 & $-96: 51$ & 1 & absent & 2475 & 19.51 \\
\hline \multirow[t]{2}{*}{$\mathrm{EQ}_{69}$} & 19810918 & 102409 & -24.67 & -71.86 & 33 & 4.9 & 546 & 15.09 .1981 & $-78: 25$ & 2 & absent & 1616 & 11.00 \\
\hline & & & & & & & 602 & 19.09 .1981 & $+12: 47$ & 5 & absent & 1109 & 06.00 \\
\hline \multirow[t]{2}{*}{$\mathrm{EQ}_{70}$} & 19810918 & 141732 & -35.24 & -110.34 & 10 & 5.0 & 547 & 15.09 .1981 & $-80: 57$ & 2 & 10 & 871 & 02.35 \\
\hline & & & & & & & 581 & 17.09 .1981 & $-22: 18$ & 1 & $4-5$ & 1596 & 11.00 \\
\hline $\mathrm{EQ}_{71}$ & 19810919 & 124910 & 10.42 & -62.81 & 63 & 5.1 & 602 & 19.09 .1981 & $+9: 54$ & 5 & absent & 2316 & 18.00 \\
\hline \multirow[t]{2}{*}{$\mathrm{EQ}_{72}$} & 19810919 & 114056 & -39.08 & -74.80 & 30 & 5.6 & 546 & 15.09 .1981 & $-76: 20$ & 2 & 10 & 1280 & 07.50 \\
\hline & & & & & & & 602 & 19.09 .1981 & $-08: 32$ & 5 & 10 & 852 & 01.30 \\
\hline \multirow[t]{2}{*}{$\mathrm{EQ}_{73}$} & 19810920 & 104820 & -23.08 & -66.63 & 234 & 5.1 & 546 & 15.09 .1981 & $-76: 20$ & 2 & 10 & 2183 & 17.00 \\
\hline & & & & & & & 602 & 19.09 .1981 & $-25: 43$ & 5 & 10 & 852 & 01.30 \\
\hline
\end{tabular}

small Scotia microplate is twisted between the both plates as a result of their horizontal movements (Earthquake Summary Poster, 2006). Two earthquakes $\mathrm{EQ}_{49}$ and $\mathrm{EQ}_{60}$ with magnitudes M 5.1 occurred in the area of South Mid-Atlantic Ridge (see Table 1). The ridge represents an oceanic rift that separates the Southern American Plate from the African one in the South Atlantic Ocean. According to plate tectonics, this ridge runs along a divergent boundary (The Mid-Atlantic Ridge, 2008). On the background of the trend in the quasistatistic electric field we observe an increase in the $E_{z}$ component of about $10 \mathrm{mV} / \mathrm{m}, 12 \mathrm{~h}$ before $\mathrm{EQ}_{46}$ and $22 \mathrm{~h}$ before $\mathrm{EQ}_{49}$. The ionosphere disturbance zone (Fig. 1b - orbit 347) is concentrated around the earthquake epicentre. Figure $1 b$ shows possible seismic pre-effects of about $2-3 \mathrm{mV} / \mathrm{m}, 78 \mathrm{~h}$ before $\mathrm{EQ}_{60}$. The obtained results of events EQ 1 (orbits 184 and 198), $\mathrm{EQ}_{46}$ (orbits 305, 348 and 403) and EQ60 (orbit 403) are summarized in the Table 1.

\subsection{Tonga-New Hebrides region and North Islands of New Zealand}

We receive satellite information for the seismic manifestations in the region in a relatively large time period 17 August-17 September 1981 when the major earthquake $\mathrm{EQ}_{41}$ with a magnitude Mw 7.9 (see Table 1) occurred along the Tonga trench on Tuesday, 1 September 1981 at 09:29:31. 


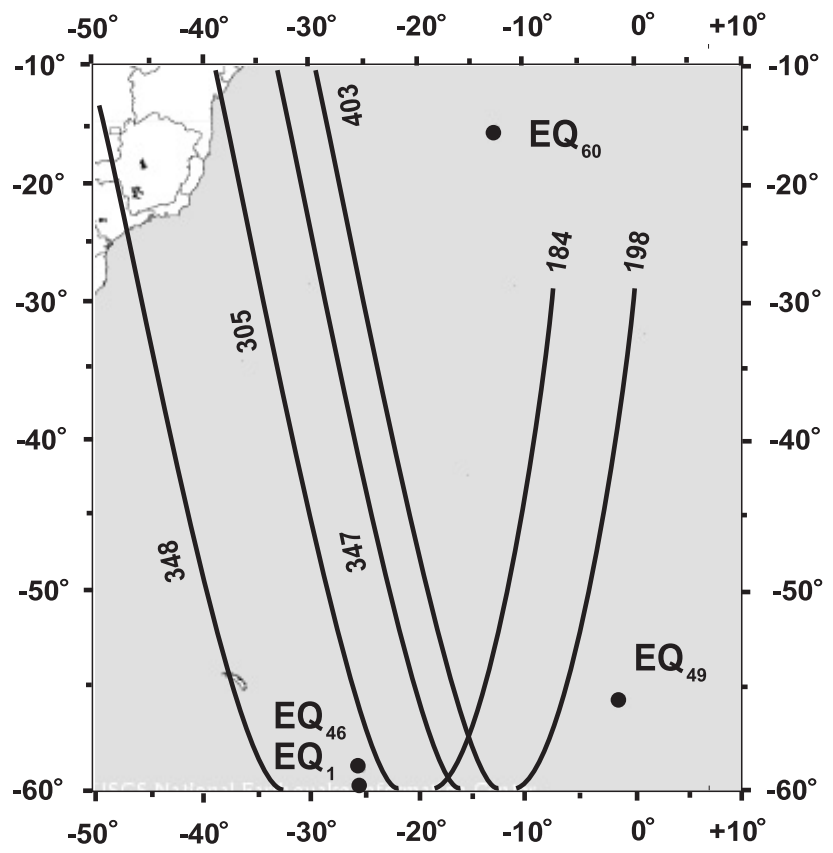

Fig. 1a. Satellite orbits 184, 198, 305, 347, 348, 403 and positions of the earthquake epicentres for periods of seismic activity in 1331 August 1981 and 28 August-9 September 1981.

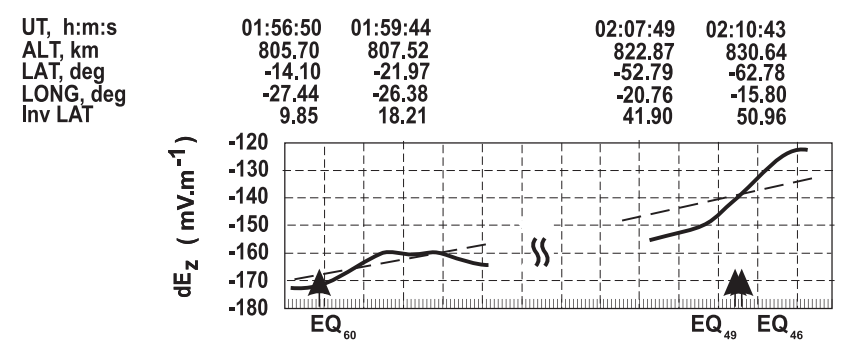

Fig. 1b. Disturbances in $E z$ component of the quasi-static field, orbit 347.

In a geophysical sense, New Zealand sits in a precarious position because it gets astride the boundary between the Pacific and Australian Plates. There are other two potential sources of large seismic activity: the Tonga-Kermadec Trench and the New Hebrides one. The Tonga Trench extends from the southern periphery of the Samoa Islands up to the connection with the Kermadec Trench. The Kermadec Trench connects the Tonga Trench to the north with the Northern Island of New Zealand to the south. The Kermadec and the Tonga trenches can be considered as one representative structural unit of Tonga-Kermadec Trench (Goff et al., 2006; Walters et al., 2006). The pass of INTERCOSMOS-BULGARIA1300 for orbits 170, 213 and 527 is shown in Fig. 2a. The earthquake epicentres take place in a relatively long and wide area. The analysis of the Fig. $2 b$ indicates that the ionospheric anomalous disturbance zone follows the same

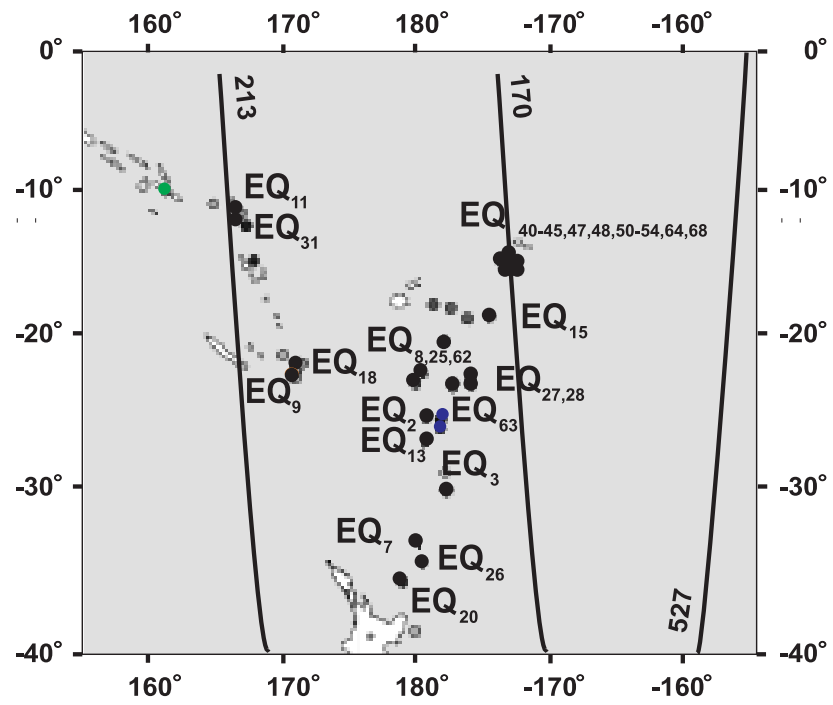

Fig. 2a. Satellite orbits $170,213,527$ and positions of the earthquake epicentres for period of seismic activity in 17 August17 September 1981.

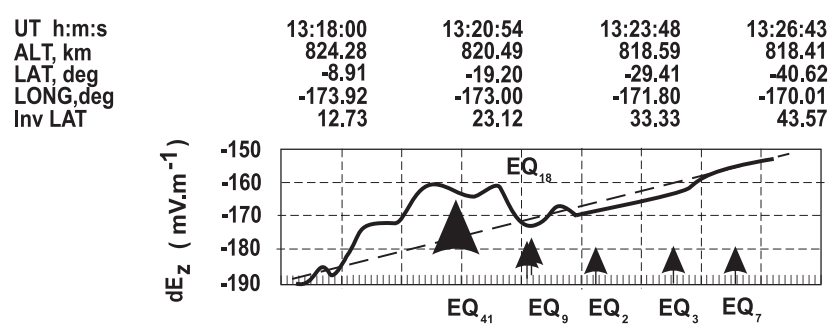

Fig. 2b. Disturbances in $E z$ component of the quasi-static field, orbit 170 .

wide latitudinal interval of earthquake epicentres. The first changes in $E_{z}$ component of the quasi-statistic electric field of about $3 \mathrm{mV} / \mathrm{m}$ are due to the cumulative seismic effect 11-42 $\mathrm{h}$ after $\mathrm{EQ}_{3}$ and $\mathrm{EQ}_{7}$. The second changes, showing an increase in $E_{z}$ component about $2 \mathrm{mV} / \mathrm{m}$, we observe at the beginning of the big bulge. The established increase could be interpreted like post-seismic effects of $\mathrm{EQ}_{2}(44 \mathrm{~h}$ after the earthquake). We observe a wide latitudinal interval with big changes and an increase in $E_{z}$ component about $10-12-18 \mathrm{mV} / \mathrm{m}$. In our opinion, the amplitudes of this unusually disturbance zone are formed by the cumulative just-post seismic effects $(7 \mathrm{~h})$ of $\mathrm{EQ}_{9}$ and forthcoming ones $\left(\mathrm{EQ}_{18}, \mathrm{EQ}_{41}\right.$ and its foreshock $\left.\mathrm{EQ}_{40}\right)$. Summarizing, the indicated big increase of about $18 \mathrm{mV} / \mathrm{m}$ might be connected with the major earthquake $\mathrm{EQ}_{41}$ with magnitude $M_{w} 7.9$ which was happened 13 days later. Any disturbances from $\mathrm{EQ}_{15}$ and $\mathrm{EQ}_{8,13,20}$ (with hypocentres on the depths $164-507 \mathrm{~km}$ and magnitudes M 4.8; 4.8; 4.9; 4.8) are not noted. In these cases the energetic levels are very low. The mentioned observations take place in a quiet day $K_{p}=3$. 


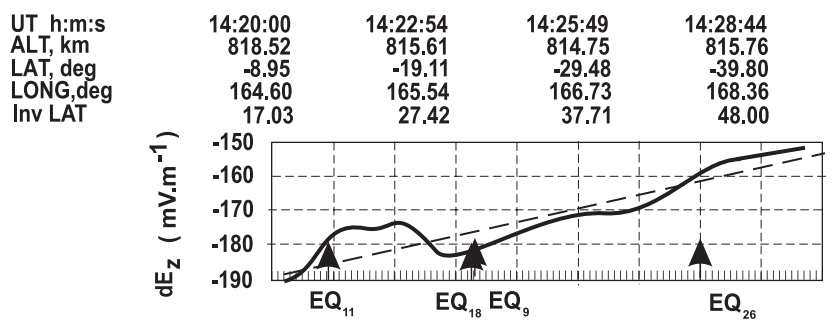

Fig. 2c. Disturbances in $E z$ component of the quasi-static field, orbit 213.

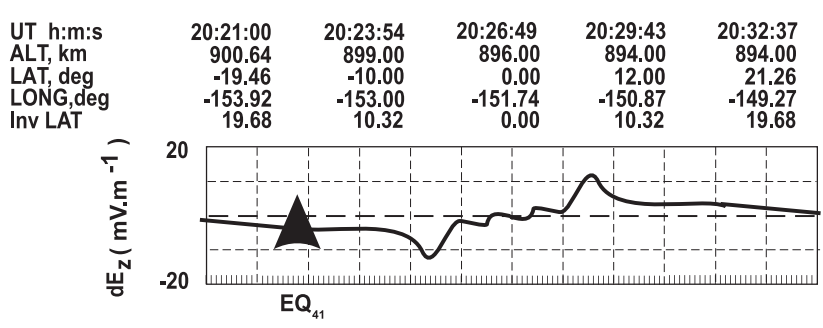

Fig. 2d. Disturbances in $E z$ component of the quasi-static field, orbit 527.

Data from orbit 213 and respectively the monitoring of seismic situation in the area of New Hebrides Trench, is used as well (Fig. 2c). The New Hebrides Trench extends from New Guinea to the east-southeast. In this case the zone of the shallow seismic manifestations coincides with the zone of convergence between the Australian plate and the New Hebrides microplate (a segment of the much larger Pacific plate). The occurred intermediate-deep earthquakes define the extent of the downgoing slab from the Australian Plate (Goff et al., 2006; Kolobov et al, 2006). It is of great interest, that the disturbances observed on Fig. 2c propose some information about earthquakes in the region, but three days later (orbit 213 on 22 August 1981). Figure 2c shows new form of the anomalous disturbance zone in a wide latitudinal interval. Any disturbances related to the major earthquake $\mathrm{EQ}_{41}$ and its foreshock $\mathrm{EQ}_{40}$ are not observed $\left(\Delta \lambda>20^{\circ}\right)$. We consider that the width of disturbance zone is probably determined by time-shift post effects from $\mathrm{EQ}_{11}$ and pre-effect $(59 \mathrm{~h})$ of $\mathrm{EQ}_{26}$. We can also observe increases in $E_{z}$ component of about $4 \mathrm{mV} / \mathrm{m}, 5 \mathrm{mV} / \mathrm{m}$ and $9-10 \mathrm{mV} / \mathrm{m}$ from $\mathrm{EQ}_{26}$, $\mathrm{EQ}_{9}$ and $\mathrm{EQ}_{18}$, respectively. These increases are shifted to the north from the earthquake epicentre. Any disturbances from $\mathrm{EQ}_{8,13,15,20,25}$ are not observed because these earthquakes are at a relatively low energetic level. There are difficulties in the determination of the influence of the events $\mathrm{EQ}_{2,3}$ and $\mathrm{EQ}_{7}$ (near to $\mathrm{EQ}_{26}$ ). Any disturbances from pair $\mathrm{EQ}_{27,28}$ are not observed $\left(\Delta \lambda>20^{\circ}\right)$ as well. It should be also noted that these measurements are made in a quiet day $\left(K_{p}=3\right)$, so the observed anomalies are not caused by a solarterrestrial disturbance. The satellite passes (orbit 527) at $\Delta \lambda=19.61^{\circ} \mathrm{E}$ (Fig. 2a) about $300 \mathrm{~h}$ after the major earth-

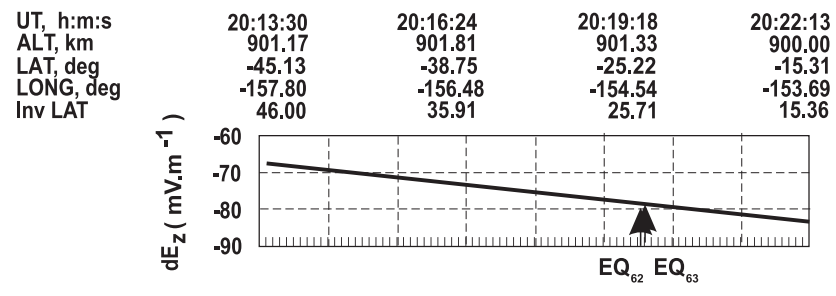

Fig. 2e. Vertical component $E z$ of the quasi-static field, orbit 527.

quake $\mathrm{EQ}_{41}$. The disturbances in the $E_{z}$ component of the quasi-static electric field: the first one to the north of the earthquake epicentres (projection over the equipotent magnetic field lines in the near-equatorial ionosphere at satellite altitude) and second one - in the magnetic conjugate region of about $12 \mathrm{mV} / \mathrm{m}$ for $\mathrm{EQ}_{41}$ are shown in Fig. $2 \mathrm{~d}$. The major earthquake event is followed by two strong aftershocks $\mathrm{EQ}_{42,43}$ the next two hours, also by a series of other ones in

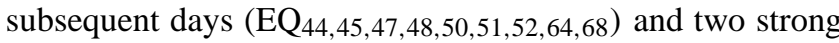
aftershocks EQ53,54 (see Table 1). Thus major and great earthquakes occur frequently in this region. It is unlikely, that these post effects could provoke an increase in $E_{z}$ component of about $12 \mathrm{mV} / \mathrm{m}$. Any post effects (Fig. 2e) from $\mathrm{EQ}_{62,63}$ cannot be observed $\left(\lambda>20^{\circ}\right)$. It should be noted that the above mentioned data are taken in a very quiet day $\left(K_{p}=1\right)$.

\subsection{Indonesian region}

The Indonesian region is one of the most seismically active zones on the Earth. It is an island-arc structure of about 17000 islands. The islands of South-East Indonesia lie at the junction of the Eurasian, Australian, Pacific and Philippine Sea Plates, resulting in rugged topography, frequent earthquakes and intensive volcanism (Indonesia, 2008). The seismic manifestations of the region, bounded between Latitudes $0^{\circ}$ to $17^{\circ} \mathrm{S}$ and Longitudes $100^{\circ} \mathrm{E}$ to $130^{\circ} \mathrm{E}, 5$ days before and after the passing of satellite (orbits 215,258 ), are shown

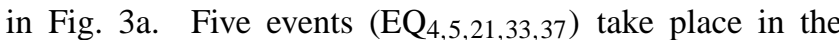
area and they are with magnitude M 4.8 during the studied time period (see Table 1). On the background of the trend, to the north of the earthquake epicentre, we observe an increase in the $E_{z}$ component of about $8 \mathrm{mV} / \mathrm{m}, 26 \mathrm{~h}$ before $\mathrm{EQ}_{21}$ (Fig. 3b). Figure 3b illustrates also the next increase in the $E_{z}$ component of about $8 \mathrm{mV} / \mathrm{m}$ to the north of $\mathrm{EQ}_{5}$ and $\mathrm{EQ}_{33}$. It is highly probable that the disturbances in the $E_{z}$ component are due to the cumulative effect of occurred $\mathrm{EQ}_{5}$ and forthcoming earthquake $\mathrm{EQ}_{33}$ (it is happened $107 \mathrm{~h}$ later). The earthquake $\mathrm{EQ}_{37}$ of magnitude $\mathrm{M} 4.9$ occurs on 19 September 1981 in the Sumatra region. The Sumatra region from the western part of Indonesia is considered as a part of the Sunda arc, which results from the convergence between the Indo-Australian and Eurasian Plates. As a product of the plate convergence, the Sumatra region is considered 


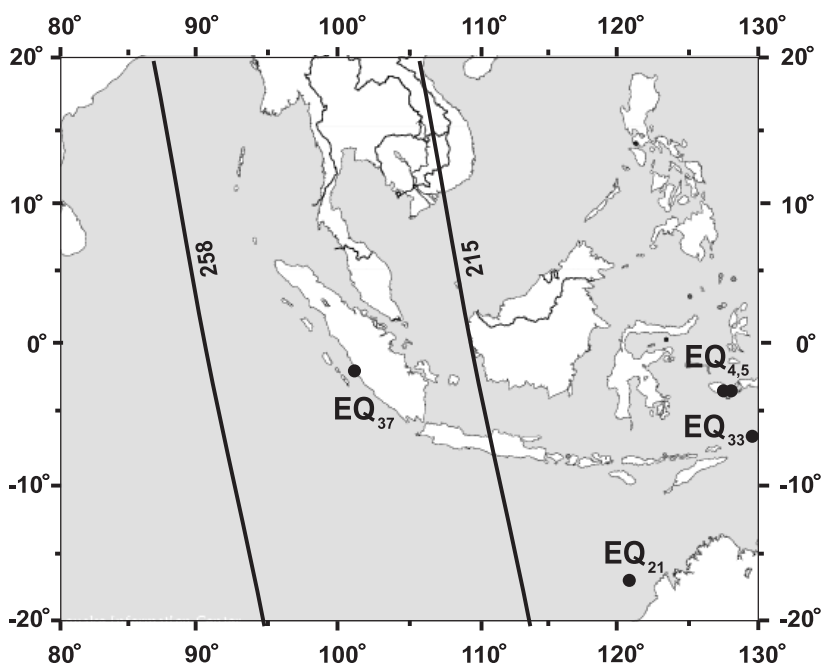

Fig. 3a. Satellite orbits 215,258 and positions of the earthquake epicentres for period of seismic activity in 12 August-1 September 1981.

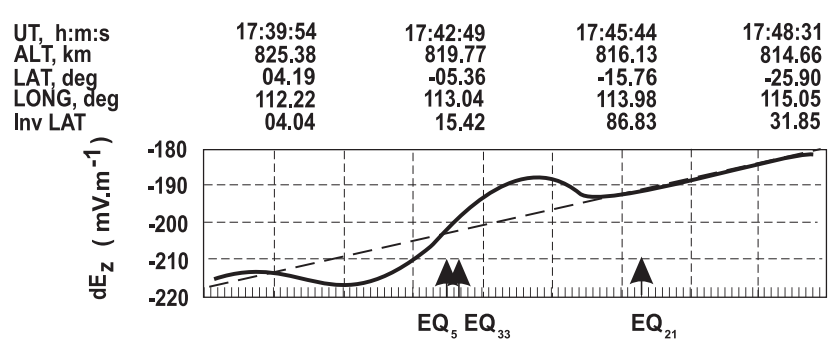

Fig. 3b. Disturbances in $E z$ components of the quasi-static field, orbit 215.

to be one of the most seismically active regions in Indonesia (Nanang T. Puspito and Gunawan Indra, 2005). The pass of INTERCOSMOS-BULGARIA-1300 (orbit 258) 84-85 h before the seismic manifestations is shown in Fig. 1c. The disturbances in the $E_{z}$ component of the quasi-static electric field are the following ones: the first one to the north of the earthquake epicentres (projection over the equipotent magnetic field lines in the near-equatorial ionosphere at satellite altitude) and second one - in the magnetic conjugate region of about $2-3 \mathrm{mV} / \mathrm{m}$ for $\mathrm{EQ}_{37}$. The both of them are shown in Fig. 1c. It should be noted that these measurements of orbits (215 and 258) are made in a quiet day $\left(K_{p}=3\right)$, so the observed anomalies could not be caused by a solar-terrestrial disturbance.

\subsection{Eastern Canada and Labrador Sea}

Two events $\left(\mathrm{EQ}_{6}, \mathrm{EQ}_{23}\right)$ are recorded on 18 August 1981 and 24 August 1981 with magnitudes M 5.1 and 4.8 in the time period 18-24 August 1981, respectively (see Table 1). $\mathrm{EQ}_{6}$ occurred in the region of Eastern Canada. The causes of earthquakes in the Eastern Canada are not well understood.

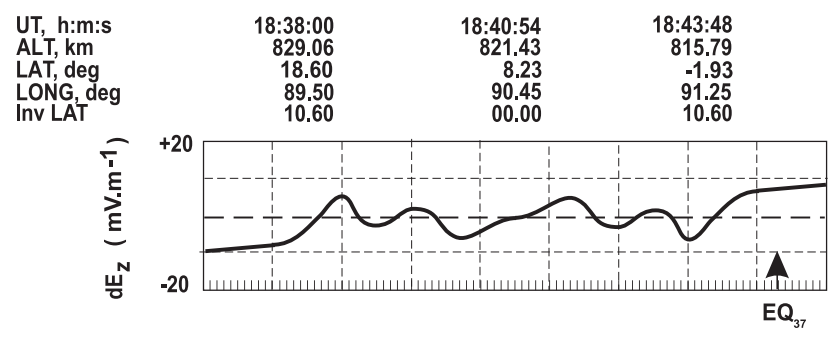

Fig. 3c. Disturbances in $E z$ components of the quasi-static field, orbit 258 .

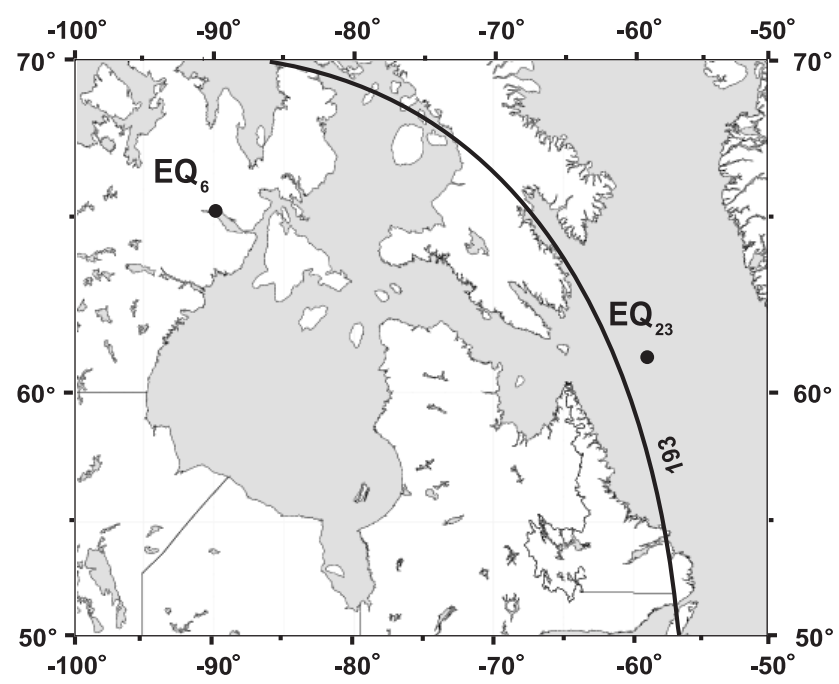

Fig. 4a. Satellite orbits 193 and positions of the earthquake epicentres for period of seismic activity in 18-24 August 1981

The Eastern Canada is a part of the relatively stable interior of the North American Plate, but not on a plate boundary. May be the North American Plate is in processes of transformation, fragmentation and division. $\mathrm{EQ}_{23}$ (see Table 1) occurred in the Labrador seismic zone on 24 August 1981 (latitude $61.22^{\circ} \mathrm{N}$, longitude $59.01^{\circ} \mathrm{W}, 11: 20: 33 \mathrm{UTC}$ and depth $10 \mathrm{~km}$ ) with $M$ 4.8. The pass of INTERCOSMOSBULGARIA-1300 for orbits 193 is shown in Fig. 4a. (Observations in) Fig. 4b indicates two anomalous disturbance zones: the first one is to the south of $\mathrm{EQ}_{6}$ with an increase in the $E_{z}$ component of about $5 \mathrm{mV} / \mathrm{m}, 62 \mathrm{~h}$ after this event and the second one - to the south of $\mathrm{EQ}_{23}$ and it is of about $10 \mathrm{mV} / \mathrm{m}, 79 \mathrm{~h}$ before this event. It should be noted that the observations are taken in a quiet day $\left(K_{p}=2\right)$ and the events $\mathrm{EQ}_{6}$ and $\mathrm{EQ}_{23}$ occurred in isolated time-space domains.

\subsection{Caribbean Region, Central America, West coast of} South America and South-West Pacific Ocean

The pre-and post seismic effects of the region bounded between Latitudes $20^{\circ} \mathrm{N}$ to $50^{\circ} \mathrm{S}$ and Longitudes $60^{\circ} \mathrm{W}$ and $120^{\circ} \mathrm{W}$ are shown in Fig. 5a. Four events $\mathrm{EQ}_{36,38,59,71}$ with 


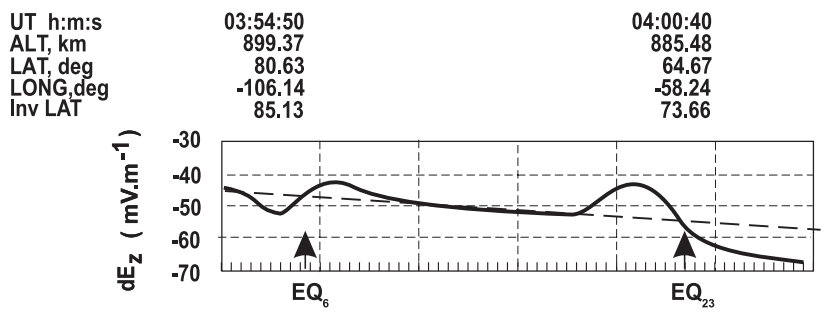

Fig. 4b. Disturbances in $E z$ component of the quasi-static field, orbit 193.

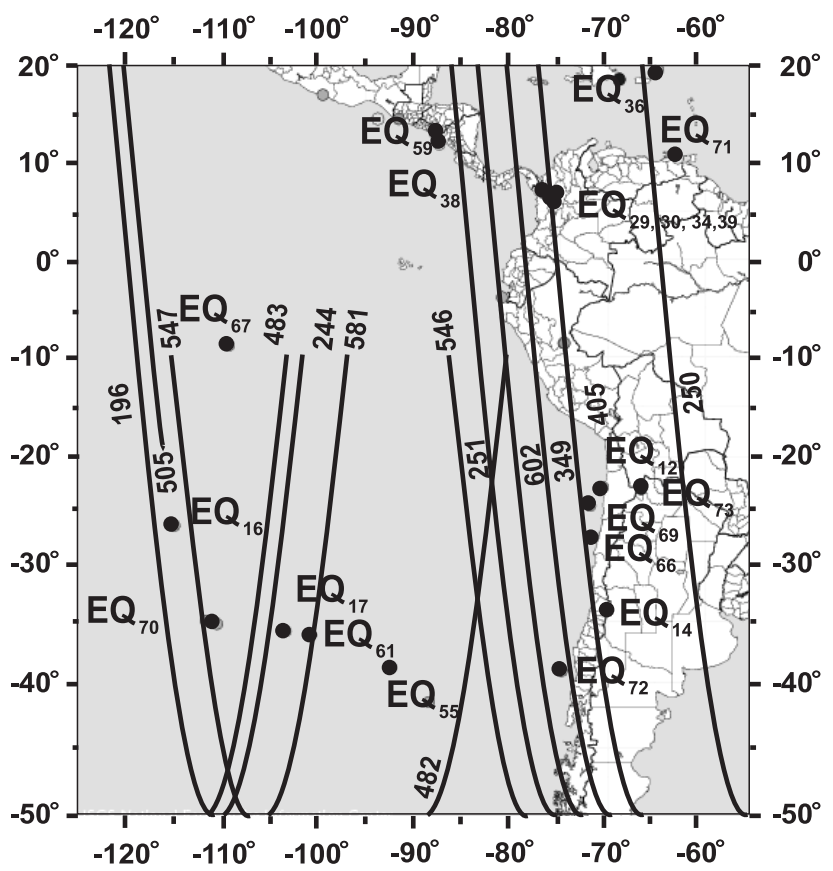

Fig. 5a. Satellite orbits 196, 244, 250, 251, 405, 505, 546, 547, 602 and positions of the earthquake epicentres for period of seismic activity in 5 August-29 September 1981.

magnitudes $M>4.8$ occurred in the region (Table 1) during the time period 29 August-19 September 1981. Their epicentres lie on the Caribbean plate (a region with relatively quiet seismicity). Any disturbances around 55-101 hours before to and 9-58 hours after these earthquakes are not marked (see Table 1). Now we do not explain these phenomena. We show also Fig. 5b (orbit 250) when the satellite passes at $\Delta \lambda=12^{\circ} \mathrm{E}-13^{\circ} \mathrm{E}$, about $11 \mathrm{~h}$ before earthquake $\mathrm{EQ}_{29}$. The earthquake $\mathrm{EQ}_{29}$ occurred in the Andes Mountains region of Peru on 25 August 1981 (latitude $6.93^{\circ} \mathrm{N}$, longitude $76.59^{\circ} \mathrm{W}, 16: 54: 38 \mathrm{UTC}$ and depth $33 \mathrm{~km}$ ) with M 5.2. Apart from the main shock, a number of earthquakes with comparatively smaller magnitudes happened in the same region like $\mathrm{EQ}_{30,34,39}$ as well (see Table 1). Two disturbances in the $E_{z}$ component of the quasi-static electric field are noted in this situation. The first one situated to the south of the earthquake epicentres (projection over the equipotential magnetic field

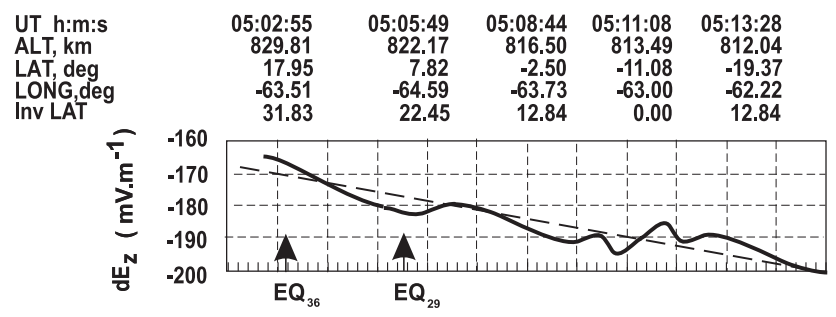

Fig. 5b. Disturbances in $E z$ component of the quasi-static field, orbit 250 .

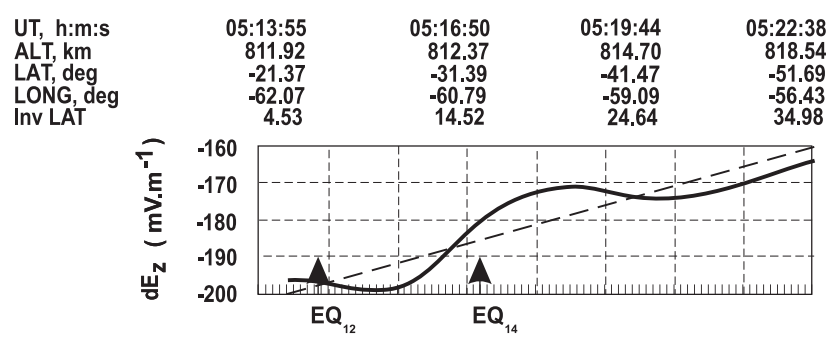

Fig. 5c. Disturbances in $E z$ component of the quasi-static field, orbit 250 .

lines in the low ionosphere at satellite altitude) and the second one - in the magnetic conjugate region of about $5 \mathrm{mV} / \mathrm{m}$ (for the main event) are shown in Fig. 5b. A similar disturbance zone from $\mathrm{EQ}_{29}$ we observe for orbit 251 (see Table 1). It should be noted that these measurements are made in a quiet day $\left(K_{p}=3\right)$, so the anomalies are not caused by a solar-terrestrial disturbance. The West coast of South America is outlined by the eastern border of the Nazca tectonic plate and it is characterized by its extremely high seismicity. There is a narrow seismic belt (100-150 km wide) between the Andes Mountain Range and the Peru-Chile Trench (Gagnon et al., 2005). Five earthquakes $\mathrm{EQ}_{12,14,66,69,72}$ in the area of the West coast of South America between $22^{\circ} \mathrm{S}$ and $40^{\circ} \mathrm{S}$ latitudes are as large as M 4.8. The seismic events occur in and near the territory of Chile. Chile is located on a plate boundary and in a subduction zone called the PeruChile Trench. The first $\mathrm{EQ}_{12}$ is an event with magnitude M 4.9 and occurs in the Province of Antofagasta. Later in the same day another earthquake $\mathrm{EQ}_{14}$ with $\mathrm{M} 4.9$ occurs in the region near Valparaiso. Figure 5c (orbit 250) illustrates a disturbance zone of about $7 \mathrm{mV} / \mathrm{m}$ and $8 \mathrm{mV} / \mathrm{m}$ in $E_{z}$ component of the quasi-static electric field, 97-120 $\mathrm{h}$ after $\mathrm{EQ}_{12}$ and $\mathrm{EQ}_{14}$, respectively. The disturbance zone is in a wide latitudinal interval. We consider that the width of disturbance zone is probably determined by time-shift post effect of $\mathrm{EQ}_{12}$ and $\mathrm{EQ}_{14}$. A similar disturbance zone from $\mathrm{EQ}_{12}$ and $\mathrm{EQ}_{14}$ we establish for orbit 251 (see Table 1). Anomalies of about $10 \mathrm{mV} / \mathrm{m}$ are marked in the $E_{z}$ components of the quasi-static electric field $8-25 \mathrm{~h}$ before $\mathrm{EQ}_{72}$ and $\mathrm{EQ}_{73}$ (see Fig. 5d - orbit 602 and Table 1). Such pre- and post seismic influence of $\mathrm{EQ}_{55,72,73}$ (orbits 349,546 ) is observed in 


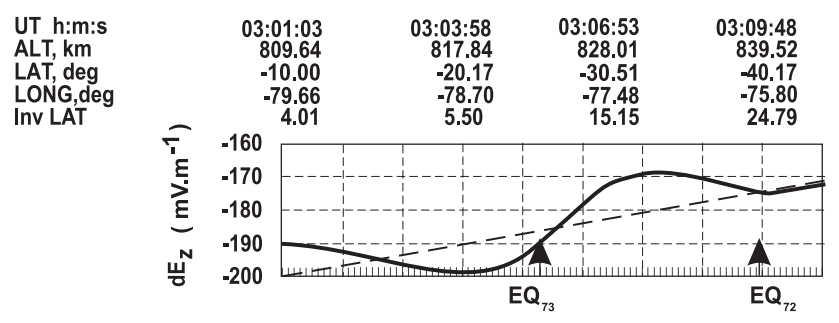

Fig. 5d. Disturbances in $E z$ component of the quasi-static field, orbit 602 .

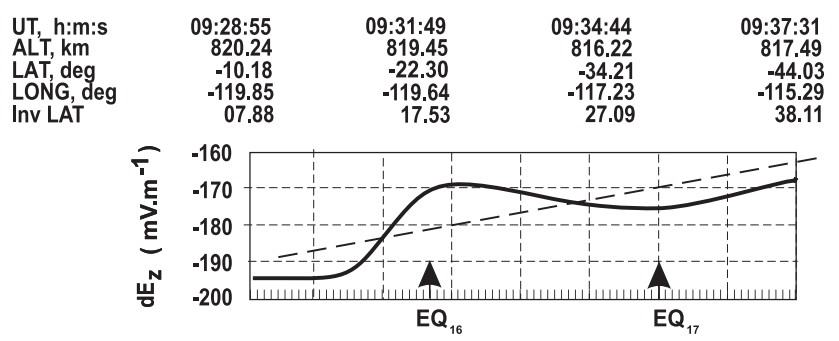

Fig. 5e. Disturbances in $E z$ components of the quasi-static field, orbit 196.

the $E_{z}$ components of the quasi-static electric field and listed in Table 1. Any disturbances (orbits 482, 546 and 602) from $\mathrm{EQ}_{66}$ and $\mathrm{EQ}_{69}$ (see Table 1) are not observed. Data from orbits 196 and 244 for observations about $\mathrm{EQ}_{16}$ and $\mathrm{EQ}_{17}$ is used as well. The satellite passes (orbit 196) about 1314 hours before $\mathrm{EQ}_{16}$ and $\mathrm{EQ}_{17}$ in the region of South-West Pacific Ocean (Fig. 5a). Figure 5e shows two disturbances in $E_{z}$ component of the quasi-static electric field in relation with seismic activity. The first change is an increase in $E_{z}$ component of about $8 \mathrm{mV} / \mathrm{m}, 13 \mathrm{~h}$ before $\mathrm{EQ}_{16}$. The second change represents another increase in $E_{z}$ component of about $10 \mathrm{mV} / \mathrm{m}, 14 \mathrm{~h}$ before $\mathrm{EQ}_{17}$. These data is taken in a medium quiet day $K_{p}=4$. We can also observe an increase in the $E_{z}$ component of about $8 \mathrm{mV} / \mathrm{m}, 55 \mathrm{~h}$ after $\mathrm{EQ}_{17}$. Any disturbances (orbit 244) from $\mathrm{EQ}_{16}, \mathrm{EQ}_{17}$ (see Table 1) are not noted. Similar anomalies in the quasi-static electric field are summarized as an increase in the vertical component of the quasi-static electric field of about $2 \mathrm{mV} / \mathrm{m}$ to $10 \mathrm{mV} / \mathrm{m}$, around $20 \mathrm{~h}$ before to and $96 \mathrm{~h}$ after earthquakes EQ61 (orbits 482 and 483), EQ66 (orbits 482 and 546) and $\mathrm{EQ}_{67}$ (orbits 505, 547 and 581). All of them are listed in Table 1.

\subsection{Kuril Island and Aleutian Islands}

We take observations over seismic events in the region with the help of two satellite orbits (240 and 283) in the time period 16 August-9 September 1981 (Fig. 5a). Two strong earthquakes in interval of about 10 days occurred in the region. The first event $\mathrm{EQ}_{19}$ (M 6.0) on 23 August 1981 took place in the area of the Kuril Islands that are located from the westernmost point of the Japanese Island of Hokkaido

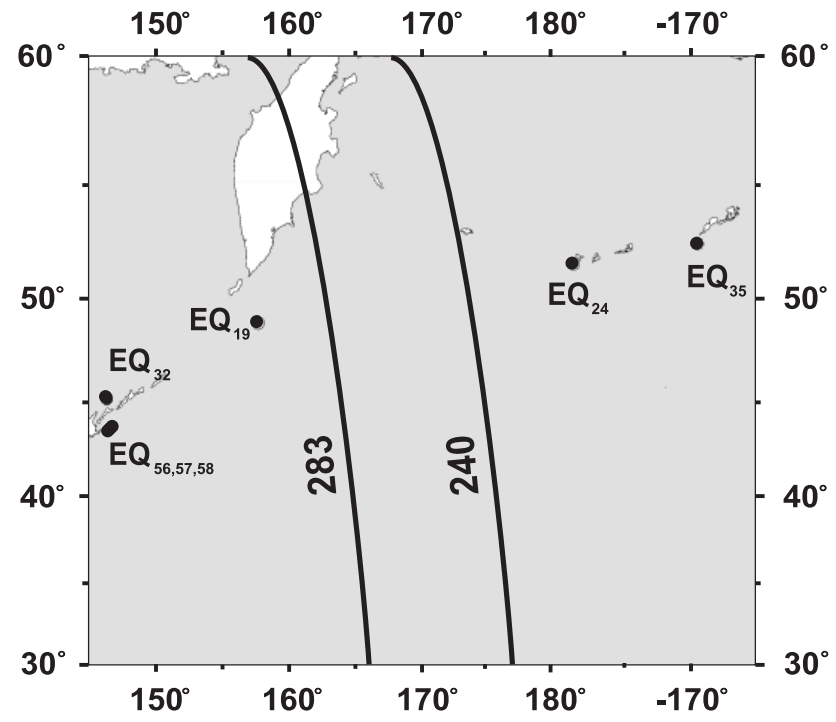

Fig. 6a. Satellite orbits 240,283 and positions of the earthquake epicentres for period of seismic activity in 23 August-5 September 1981 .

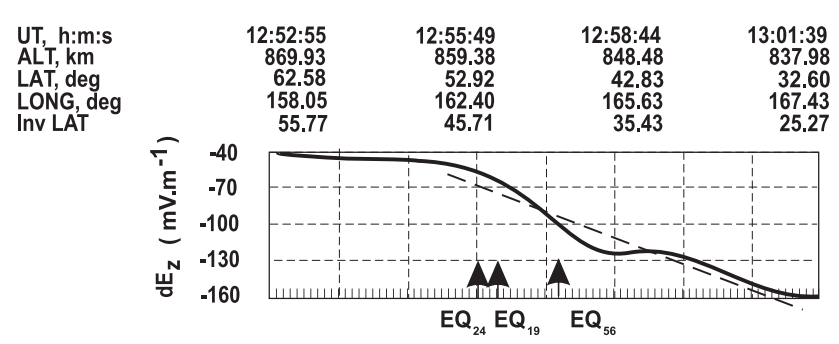

Fig. 6b. Disturbances in $E z$ component of the quasi-static field, orbit 283 .

to the southern tip of the Kamchatka Peninsula. The Kuril Trench was formed by the subduction of the Pacific plate under the North American plate and extends from the central area of Kamchatka to Hokkaido. The Kuril Trench is one of the most active seismogenic regions due to the subduction of the Pacific Ocean Plate beneath Hokkaido. Figure $5 \mathrm{~b}$ (orbit 283) shows an increase in the $E_{z}$ component of about $10 \mathrm{mV} / \mathrm{m} 92 \mathrm{~h}$ after the $\mathrm{EQ}_{19}$ event. The ionospheric disturbance zone shows concentration around the earthquake epicentre. Probably, it is not impossible that there is also influence of $\mathrm{EQ}_{24}$ (the satellite passed $72 \mathrm{~h}$ after the earthquake $\mathrm{EQ}_{24}$ ). A strong earthquake $\mathrm{EQ}_{56}$ (M 6.6) occurs in the region of Aleutian Islands, about 10 days later, on 3 September 1981. Another earthquake $\mathrm{EQ}_{56}$ occurs near Shikotan Island, in the South Kuril Island Group of Russian Far East. On the background of the trend in the quasi-static electric field, we establish an increase in the $E_{z}$ component of about $15 \mathrm{mV} / \mathrm{m}$ (Fig. $5 \mathrm{~b}$ ), $157 \mathrm{~h}$ before this event. The ionospheric disturbance zone is shifted to the south of the earthquake epicentre. The information is taken in a medium 
quiet day $K_{p}=5$. Any disturbances from aftershocks $\mathrm{EQ}_{57}$, $\mathrm{EQ}_{58}$ and $\mathrm{EQ}_{32}$, events of relatively low energetic levels, are not marked. Several anomalies in vertical component $E z$ of the quasi-static electric field related to $\mathrm{EQ}_{24}$ are listed in Table 1. It is difficult to determine the influence of the event $\mathrm{EQ}_{35}$ that is in vicinity of $\mathrm{EQ}_{24}$.

The appearance of similar anomalies in vertical component $E_{z}$ of the quasi-static electric field could be provoked by $\mathrm{EQ}_{24}, \mathrm{EQ}_{35}$ and $\mathrm{EQ}_{65}$ in the South Pacific and Southern Iran (see Table 1).

\section{Summary, discussion and conclusions}

Quasi-static electric fields anomalies in the upper ionosphere associated with seismic activity during August-September 1981 are investigated by using the observation data of the INTERCOSMOS-BULGARIA-1300 satellite in conditions of magnetically very quiet, quiet and medium quiet days. The observations suggest the presence of quasi-static electric field disturbances related to seismic activity above earthquake sources in the Southern and the Northern Hemispheres at different latitudes. The dates of seismic events, their origin time, locations of epicentre, magnitude and depth in the observed period are obtained from United State Geological Survey (USGS) website.

The analysed period is short and includes 38 days. New specialized software has been used for processing of ionospheric disturbance zones on the background of the trend for all orbits' tracing and of data for the represented plates of the Earth. The obtained results about 73 events selected from INTERCOSMOS-BULGARIA-1300 data-base are summarized in the Table 2. We exclude the possible effects from 2 foreshocks and 14 aftershocks. Twenty six orbits for observation of 92 main shocks are used. No disturbances from 35 events are observed. In the paper 52 positive pre- and postpossible effects are shown as:

- 25 pre-effects of nighttime and 2 pre-effects of daytime observations;

- 21 post-effects of nighttime and 4 post-effects of daytime observations.

We focus our attention on the considerable rising of data only of nighttime observations for the ionospheric anomalies that are in possible associations with earthquakes.

\subsection{Light earthquakes}

Over the earthquake source regions of earthquakes with magnitude M 4.8-4.9 at different latitudes, sometimes, but not always, disturbances (bulges) in the quasi-static electric field could be observed. Disturbances from light earthquakes with depth $>117 \mathrm{~km}$ are not established because these seismic manifestations are at a relatively low energetic level and in a great depth. There are pre-effect disturbances of about $3-$ $10 \mathrm{mV} / \mathrm{m} 12 \mathrm{~h}$ before for all different latitudes and $80 \mathrm{~h}$ after earthquakes for low and middle latitudes.

\subsection{Moderate earthquakes}

\subsubsection{Concerning near equatorial latitudes}

The anomalies in the quasi-static electric field at nearequatorial latitudes show mainly an increase in the vertical component $E_{z}$ of about $5 \mathrm{mV} / \mathrm{m}$ during a period of $11-$ $20 \mathrm{~h}$ before moderate earthquakes in Northern and Southern Hemispheres. Similar effects are also observed in the magnetic conjugate region. Disturbances are observed for $\Delta \lambda \leq 13^{\circ}$. Over sources of moderate earthquakes $\left(\mathrm{EQ}_{29}\right.$ and its aftershocks $\mathrm{EQ}_{30,34,39}$ ) and light earthquake $\mathrm{EQ}_{37}$, the electric field is perpendicular to the magnetic field line (or to the magnetic field) for orbits 250,251 , and 258. Ions and electrons are moving perpendicular to the plane determined by the electric and magnetic vectors. They can not immediately compensate the charge that causes the electric field, so this field is expanded into a large area.

\subsubsection{Concerning low latitudes}

Numerous ionospheric anomalies in the quasi-static electric field at low latitudes indicate an increase in the vertical components $E z$ of about $10-8 \mathrm{mV} / \mathrm{m}$ (in the cases of $\Delta \lambda \leq 1^{\circ}-$ $14^{\circ}$ ) to $10-2 \mathrm{mV} / \mathrm{m}$ (for $\Delta \lambda \leq 6^{\circ}-16^{\circ}$ ) around $13-25 \mathrm{~h}$ to 7-19 h respectively before and after moderate earthquakes which are related to seismic events in the Southern Hemisphere. There are not observations about analogous disturbances $100 \mathrm{~h}$ before and $9 \mathrm{~h}$ after moderate earthquakes in cases of seismic activity in the Northern Hemisphere.

\subsubsection{Concerning high and middle latitudes}

The observed anomalies in ionospheric zones, that have supposed relations with earthquakes in regions at high and middle latitudes of the Southern and Northern Hemisphere, are summarized as an increase in the vertical component $E z$ of about $10 \mathrm{mV} / \mathrm{m}$ (in the cases of $\Delta \lambda \leq 1^{\circ}-18^{\circ}$ ) to $2 \mathrm{mV} / \mathrm{m}$ (for $\Delta \lambda \leq 5^{\circ}-18^{\circ}$ ) around $80 \mathrm{~h}$ to $96 \mathrm{~h}$ before and after moderate seismic manifestations.

The recent results for high latitudes and the results from our previous papers for Southern Ocean and Greenland Sea (Gousheva et al., $2008 \mathrm{~b}$ ) confirm the empirical models of Heppner (1977), Heppner and Maynard (1987) and the electric convection field model proposed by Heelis et al. (1982).

The obtained results strengthen our previous studies and conclusions for middle latitudes (Gousheva et al., 2008a). Often the intense disturbances in electric field components are especially observed at high latitudes under complicated conditions and these disturbances are marked usually in the open field lines that provoke rare penetration in geomagnetic mid-latitudes. 
Table 2. General resuts from observations.

Total number of earthquakes from USGS website

Total number of positive, uncertain and negative effects from main shocks for twenty six orbits 92

$\begin{array}{ll}\text { Total number of positive and negative effects } & 87\end{array}$

Number of possible positive effects $\quad 52$

$\begin{array}{ll}\text { Number of pre effects } & 27\end{array}$

Number of nighttime pre effects for different latitudes $\quad 25$

\begin{tabular}{llllllll}
\hline \multicolumn{2}{c}{ Near-equatorial latitudes } & \multicolumn{3}{c}{ Low latitudes } & \multicolumn{3}{c}{ Middle and hight latitudes } \\
\hline 2 & 2 & 2 & 6 & 1 & $2+1$ & $7+1$ & $1+0$ \\
$-\Delta t, h$ & $-\Delta t, h$ & $-\Delta t, h$ & $-\Delta t, h$ & $-\Delta t, h$ & $-\Delta t, h$ & $-\Delta t, h$ & $-\Delta t, h$ \\
$\leq 12$ & $\leq 11-20$ & $\leq 12$ & $\leq 13-25$ & $\leq 306$ & $\leq 12$ & $\leq 80$ & $\leq 80$ \\
$M \Delta \lambda$, deg & $M \Delta \lambda$, deg & $M \Delta \lambda$, deg & $M \Delta \lambda$, deg & $M \Delta \lambda$, deg & $M \Delta \lambda$, deg & $M \Delta \lambda$, deg & $M \Delta \lambda$, deg \\
$4.8-4.9 \leq 1-9$ & $5-6 \leq 13$ & $4.8-4.9 \leq 1-9$ & $5-6 \leq 1-14$ & $7-8 \leq 1$ & $4.8-4.9 \leq 1-9$ & $5-6 \leq 1-18$ & $6-7 \leq 18$ \\
\hline
\end{tabular}

\begin{tabular}{|c|c|c|c|c|c|c|}
\hline \multicolumn{6}{|c|}{ Number of nighttimepost effects for different latitudes } & \multirow{2}{*}{$\frac{21}{\text { Hight latitudes }}$} \\
\hline \multicolumn{3}{|c|}{ Low latitudes } & \multicolumn{3}{|c|}{ Middle latitudes } & \\
\hline 1 & 5 & 1 & 7 & 3 & 1 & 3 \\
\hline$+\Delta t, h$ & $+\Delta t, h$ & $+\Delta t, h$ & $+\Delta t, h$ & $+\Delta t, h$ & $+\Delta t, h$ & $+\Delta t, h$ \\
\hline$\leq 80$ & $\leq 7-19$ & $\leq 300$ & $\leq 80$ & $\leq 96$ & $\leq 91$ & $\leq 96$ \\
\hline$M \Delta \lambda, \operatorname{deg}$ & $M \Delta \lambda, \mathrm{deg}$ & $M \Delta \lambda, \operatorname{deg}$ & $M \Delta \lambda, \operatorname{deg}$ & $M \Delta \lambda, \operatorname{deg}$ & $M \Delta \lambda, \operatorname{deg}$ & $M \Delta \lambda, \operatorname{deg}$ \\
\hline $4.8-4.9 \leq 1-14$ & $5-6 \leq 6-16$ & $7-8 \leq 20$ & $4.8-4.9 \leq 1-14$ & $5-6 \leq 1-14$ & $6-7 \leq 9$ & $5-6 \leq 1-14$ \\
\hline
\end{tabular}

\subsection{Strong and major earthquakes}

\subsubsection{Concerning low latitudes of the Southern Hemisphere}

The observed anomalies in ionospheric zones, that have supposed relations with earthquakes in regions at low latitudes of the Southern Hemisphere, are summarized as an increase in the vertical component $E z$ of about $18 \mathrm{mV} / \mathrm{m}$ (for $\Delta \lambda \leq 1^{\circ}$ ) to $12 \mathrm{mV} / \mathrm{m}$ (for $\Delta \lambda \leq 20^{\circ}$ ) around $306 \mathrm{~h}$ to $300 \mathrm{~h}$ before and after major seismic manifestations.

\subsubsection{Concerning middle latitudes of the Northern Hemi- sphere}

The observed anomalies in ionospheric zones, that could be related to earthquakes in regions at middle latitudes of the Northern Hemisphere, are summarized as an increase in the vertical component $E z$ of about $15 \mathrm{mV} / \mathrm{m}$ (for $\Delta \lambda \leq 18^{\circ}$ ) to $10 \mathrm{mV} / \mathrm{m}$ (for $\Delta \lambda \leq 9^{\circ}$ ) around $153 \mathrm{~h}$ to $91 \mathrm{~h}$ before and after strong seismic manifestations.

The present statistical study of numerous ionospheric data permits to propose several conclusions:

- The study shows possible relations between the amplitude (or trend) of the disturbance zone, the magnitude $M$, depth $D$ of the seismic event, and the distance from the satellite to the earthquake epicentre $(r \mathrm{~km}$ and $\Delta \lambda)$. Disturbances above $10 \mathrm{mV} / \mathrm{m}$ are only observed for strong and major earthquakes. No disturbances are observed for moderate earthquakes at $D>234 \mathrm{~km}$ and for light earthquakes at $D>117 \mathrm{~km}$. Generally the disturbances are observed for $\Delta \lambda<20^{\circ}$.

- During, the study two forms of quasi-static electric field disturbance zones in the upper ionosphere are recognized. The bulge with different amplitudes is observed in very narrow seismic belts where the earthquake manifestations are numerous. The wave discordance is established in regions with limited numbers of seismic events.

- The ionosphere disturbance zones are generated several days before the main shock. The ionosphere zones of electric field disturbances in cases of earthquakes in the Southern Hemisphere are shifted to the north from the earthquake epicentres. The same ionospheric zones (of electric field disturbances) related to earthquakes in the Northern Hemisphere take place to the south of the earthquake epicentres. This is connected with the electric field projection along magnetic field lines into the low ionosphere at satellite altitudes. The effects are also observed in the magnetic conjugate region as it has been already noted by Chmirev et al. (1989) and Gousheva et al. (2008b). Finally we suppose the presence of a source of quasi-static electric field of a seismic origin.

- At the moment of the main shock the disturbance zone is located above the epicentre and its amplitude increases.

- The disturbance zone changes its position with the time. It migrates back in latitude several hours to 2-3 days later. 
- The data about the seismic situation 15 days before and after the observations in regions with high seismic activity and 5 days before and after observations for regions of moderate and low seismicity gives us a possibility to separate fore- and after-shocks from the main shocks.

- Pre- and post cumulative effects of several events are established very often. In several cases it is difficult to determine the predominant influence of one seismic phenomena.

- We found similar pre- and post effects during observations at magnetically very quiet, quiet and medium quiet days for ionospheric zones of electric field disturbances in cases of earthquakes in the Northern and Southern Hemisphere.

- The ionospheric disturbance takes place above seismic active territories, mainly along the boundaries of the plates because these boundaries represent tectonic structures of the most considerable energy accumulation and liberation.

- The anomalous disturbance zone persists in a wide latitudinal interval and could represent one of numerous other indications for the activity of earthquake sources.

The obtained results about effects in the quasi-static field of the order $10 \mathrm{mV} / \mathrm{m}$ represent a confirmation of the new method for computation of the electric field in the atmosphere and the ionosphere over active faults proposed by Sorokin (2005a, 2006).

The final results of the investigations indicate that the ionospheric anomalies, as phenomena accompanying the seismogenic processes, could be considered eventually as possible pre-, co- and post- earthquake effects.

Edited by: P. F. Biagi

Reviewed by: P. Velinov and another anonymous referee

\section{References}

Alperovich, L. and Fedorov, E.: Perturbation of atmospheric conductivity as a cause of the lithosphere-ionosphere interaction, in: Atmospheric and Ionospheric Electromagnetic Phenomena Associated with Earthquakes, edited by: Hayakawa M., TERRAPUB, Tokyo 591-596, 1999.

Chmyrev, V. M., Isaev, N. V., Bilichenko, S. V., and Stanev, G. A.: Observation by space-born detectors of electric field and hydromagnetic waves in the ionosphere over an earthquake centre, Phys. Earth Plan. In., 57(1-2), 110-114, 1989.

Earthquake Summary Poster, available at: http://earthquake.usgs. gov/eqcenter/eqarchives/poster/2006/20060820.php, last access: 15 April, 2008.

Gagnon, K., Chadwell, C., Norabuena, E.: Measuring the onset of locking in the Peru-Chile Trench with GPS and acoustic measurements, Nature, 434, 205-208, 2005.
Goff, J., Walters, R., and Callaghan, F.: Tsunami Source Stady, National Institute of Water and Atmospheric Research, New Zeland, Enviroment Waikato Technical Report 2006/49, 1 pp., 26 pp., 2006.

Gousheva, M., Glavcheva, R., Danov, D., Angelov, P., and Hristov, P.: Influence of earthquakes on the electric field disturbances in the ionosphere on board of the Intercosmos-Bulgaria-1300 satellite, Compt. Rend. Acad. Bulg. Sci., 58(8), 911-916, 2005 a.

Gousheva, M., Glavcheva, R., Danov, D., Angelov, P., Hristov, P., Kirov, B., and Georgieva, K.: Observation From The Intercosmos-Bulgaria-1300 Satellite Of Anomalies In The Ionosphere Associated With Seismic Activity, Poster Proceedings of 2nd International Conference on Recent Advances in Space Technologies: Space in the Service of Society, RAST'2005, 911 June 2005, Istanbul, Turkey, 119-123, 2005 b.

Gousheva, M., Glavcheva, R., Danov, D., and Boshnakov, I.: Satellite observations of ionospheric disturbances associated with seismic activity, Compt. Rend. Acad. Bulg. Sci., 59(8), 821-826, 2006 .

Gousheva, M., Glavcheva, R., Danov, D., Angelov, P., Hristov, P., Kirov, B, and Georgieva, K.: Satellite monitoring of anomalous effects in the ionosphere probably related to strong earthquakes, Adv. Space Res., 37(4), 660-665, 2006b.

Gousheva, M., Glavcheva, R., Danov, D., Hristov, P., Kirov, B., and Georgieva, K.: Possible pre- and post- earthquake effects in the ionosphere, IEEE Proceedings of $3^{r d}$ International Conference on Recent Advances in Space Technologies, 14-16 June 2007, Istanbul, Turkey, 754-759, 2007.

Gousheva, M., Glavcheva, R., Danov, D., Hristov, P., Kirov, B, and Georgieva, K.: Electric field and ion density anomalies in the mid latitude ionosphere: Possible connection with earthquakes?, Adv. Space Res., 42(1), 206-212, 2008a.

Gousheva, M., Danov, D., Hristov, P., and Matova, M.: Quasi-static electric fields phenomena in the ionosphere associated with preand post earthquake effects, Nat. Hazards Earth Syst. Sci., 8, 101-107, 2008b, http://www.nat-hazards-earth-syst-sci.net/8/101/2008/.

Hepper, J. P.: Empirical models of high-latitude electric field, J. Geophys. Res., 82, 1115-1125, 1977.

Heppner, J. P. and Maynard N. C.: Empirical High-Latitude Electric Field Models, J. Geophys. Res., 92, 4467-4489, 1987.

Heelis, R. A., Lowell J. K., and Spiro R. W.: A model of the highlatitude ionospheric convection, J. Geophys. Res., 87, 63396345, 1982.

Indonesia: available at: http://earthquake.usgs.gov/regional/world/ indonesia/seismotectonics.php, last access: 10 June 2008.

Kim, V. P and Hegai, V. V.: A possible presage of strong earthquake in the night-time mid- latitude F2 region ionosphere, in: Atmospheric and Ionospheric Electromagnetic Phenomena Associated with Earthquakes, Hayakawa M., TERRAPUB, Tokyo, 619-628, 1999.

Kolobov, V. Y., Tikunov, Y. V., Travin, A. V., and Akimtsev, V. A.: Geochemistry of Volcanic Rocks of the New Hebrides Trench: Evidence of Changes in Geodynamic Regime, Geochemistry International, 43, 29-38, 2006.

Nanang, T.: Puspito and Gunawan Indra: Tsunami sourses in the Sumatra region, Indonesia and simulation of the 26 December 2004 Aceh tsunami, ISET Journal of Earthquake Technology, 42, 111-125, 2005. 
Pedersen, A., Cattell, C. A., Falthammar, C.-G., Formisano, V., Lindqvist, P.-A., Mozer, F., and Torbert, R.: Quasistatic electric field measurements with spherical double probes on the GEOS and ISEE satellites, Space Sci. Rev., 37, 269-312, 1984.

Pedersen, A., Mozer, F., and Gustafsson, G.: Electric field measurements in a tenuous plasma with spherical double probes, in: Measurement Techniques in Space Plasmas: Fields (AGU Geophysical Monograph, 103), edited by: Borovsky, J., Pfaff, R., and Young, D., American Geophysical Union, 1-12, 1998.

Sorokin, V. M., Chmyrev, V. M., and Yaschenko, A. K.: Electrodynamic model of the lower atmosphere and ionosphere coupling, J. Atmos. Solar-Terr. Phys., 63, 1681-1691, 2001a.

Sorokin, V. M., Chmyrev, V. M., and Yaschenko, A. K.: Perturbation of the electric field in the Earth-ionospherhe layer at the charget aerosols injection, Geomagnetism and Aeronomy, 41(2), 187-191, 2001b.

Sorokin, V. M. and Chmyrev, V. M..: Electrodynamic model of ionospheric precursors to earthquakes and certain types of disasters, Geomagnetism and Aeronomy, 42, 784-792, 2002.
Sorokin, V. M., Chmyrev, V. M., and Yaschenko, A. K.: Possible DC electric field in the ionosphere related to seismicity, Advances in Space Research, 37, 4, 666-670, 2006.

Sorokin, V. M. and Yaschenko, A. K.: Electric field disturbances in the Earth-ionosphere layer, Adv. Space Res., 26(8), 1219-1223, 2000.

Sorokin, V. M., Yaschenko A. K., Chmyrev, V. M., and Hayakawa, M.: DC electric field amplification in the Mid-latitude ionosphere over seismically active faults, Nat. Hazards Earth Syst. Sci., 5, 661-666, 2005,

http://www.nat-hazards-earth-syst-sci.net/5/661/2005/.

The Mid-Atlantic Ridge: 2nd International Mid Atlatic Ridge Expert Workshop, 27-28 March 2008, Azores, Potugal, available at: http://whc.unesco.org/en/activities/504/, last access: 14 June, 2008.

Walters, R., Goff, J., and Wang, K.: Tsunamigenic sources in the bay of plenty, New Zealand, Science of Tsunami Hazards, 24, 339-359, 2006. 